Published in final edited form as:

Bone. 2013 June ; 54(2): 264-271. doi:10.1016/j.bone.2012.11.038.

\title{
OSTEOCYTE APOPTOSIS
}

\author{
Robert L. Jilka ${ }^{1}$, Brendon Noble ${ }^{2}$, and Robert S. Weinstein ${ }^{1}$ \\ ${ }^{1}$ Division of Endocrinology \& Metabolism, Center for Osteoporosis and Metabolic Bone Diseases, \\ Central Arkansas Veterans Healthcare System, 4301 W. Markham, Slot 587, University of \\ Arkansas for Medical Sciences, Little Rock, AR 72205
}

${ }^{2}$ School of Science, Technology \& Health, University Campus Suffolk, Waterfront Building, 19 Neptune Quay, Ipswich IP4 1QJ, United Kingdom

\begin{abstract}
Apoptotic death of osteocytes was recognized over 15 years ago, but its significance for bone homeostasis has remained elusive. A new paradigm has emerged that invokes osteocyte apoptosis as a critical event in the recruitment of osteoclasts to a specific site in response to skeletal unloading, fatigue damage, estrogen deficiency and perhaps in other states where bone must be removed. This is accomplished by yet to be defined signals emanating from dying osteocytes, which stimulate neighboring viable osteocytes to produce osteoclastogenic cytokines. The osteocyte apoptosis caused by chronic glucocorticoid administration does not increase osteoclasts; however, it does negatively impact maintenance of bone hydration, vascularity, and strength.
\end{abstract}

\section{Keywords \\ osteocytes; apoptosis; RANKL; bone remodeling; mechanical force; ovariectomy; glucocorticoid excess}

\section{Introduction}

For many years the bone-bound osteocyte had been considered a relatively inactive cell with a broadly unknown role in bone. While it clearly formed an intricate and pervasive cell and fluid-filled network in all human bones and those of most if not all other chordates, the lack of evidence of dynamic behavioral change in osteocytes during conditions of damage or disease precluded clues as to their function. The discovery that osteocytes died by apoptosis under the conditions of high turnover associated with bone modeling (during growth), and remodeling associated with pathological conditions and damage, was one of the first drivers to the renaissance of these cells [1]. Since that time, osteocytes have been shown to secrete a variety of factors that regulate osteoclast and osteoblast differentiation and local mineralization, as well as endocrine factors that modify kidney function. However, progress in delineating the biological significance of osteocyte apoptosis has been arguably more difficult.

Corresponding author's address: Robert L. Jilka, Ph.D., University of Arkansas for Medical Sciences, Division of Endocrinology and Metabolism, Slot 587, Little Rock, AR 72211, 501-686-7896 (w), 501-247-0744 (c), rljilka@uams.edu.

Publisher's Disclaimer: This is a PDF file of an unedited manuscript that has been accepted for publication. As a service to our customers we are providing this early version of the manuscript. The manuscript will undergo copyediting, typesetting, and review of the resulting proof before it is published in its final citable form. Please note that during the production process errors may be discovered which could affect the content, and all legal disclaimers that apply to the journal pertain. 
A variety of conditions and factors can activate the apoptotic death pathway including DNA damage, hypoxia, loss of integrin signaling, and activation of death receptors, each of which culminates in an increase in the permeability of the outer mitochondrial membrane. The latter is accomplished by activation of Bax and Bak - the pro-apoptotic members of the Bcl-2 family of proteins - resulting from a conformational change that exposes cryptic epitopes at their N-termini [2]. Exposure of these epitopes promotes the formation of Bax and Bak homo-oligomers, as well as a small number of hetero-oligomers within the outer mitochondrial membrane [3]. These oligomers form channels that facilitate the release of cytochrome $\mathrm{c}$ from the mitochondria into the cytoplasm where it promotes activation of latent caspases, a family of endopeptidases [4]. The initiator caspases (caspase-2, -8, -9, and -10) activated by cytochrome c subsequently activate the effector caspases (caspase- $3,-6$, and -7) that are responsible for demolition of the cell. They degrade a variety of critical intracellular proteins, and also activate other latent enzymes including a specific DNase that cleaves at exposed internucelosomal sites [5]. During apoptosis, the phosphatidyl serine molecules within the phospholipid bilayer of the surface membrane "flip" from the inner to the outer surface of the bilayer, and the cells eventually break apart into vesicles, also known as apoptotic bodies. They are usually phagocytosed by macrophages, but other cell types are also capable of ingesting them.

Besides apoptosis, there are a number of other regulated cell death mechanisms, most of which do not involve mitochondrial regulation of caspase activation [6]. A notable example is necroptosis, which is stimulated by oxidative stress, tumor necrosis factor, or activation of toll-like receptors. This form of regulated necrosis involves stimulation of lipase activity, lipid oxidation, and permeabilization of lysosomal membranes [7]. It is currently unknown whether such alternative death pathways contribute to osteocyte cell death.

Apoptosis serves many functions including removal of cells that are no longer functioning properly, removal of superfluous cells during development, elimination of potentially cancerous cells, and regulation of tissue size, including bone. Indeed, apoptosis of shortlived osteoclasts and osteoblasts contributes to the regulation bone mass [8, 9]. Because of their location within the bone matrix, and the extensive dendritic network that allows communication with each other, with the vasculature and with the bone surface, osteocytes are ideally suited for orchestrating the appropriate targeting of osteoclasts and osteoblasts in both anabolic and catabolic situations. After reviewing the histologic detection of apoptotic osteocytes, we will discuss recent advances showing that osteocyte apoptosis plays a key role in orchestrating the local development of osteoclasts. We will also review the skeletal impact of glucocorticoid-stimulated apoptosis of osteocytes.

\section{Histologic detection of apoptotic osteocytes}

In clear contrast to the situation in soft tissues, the loss of individual osteocytes in bone is relatively easy to monitor due to their presence within a lacunar system constructed within the calcified bone matrix. In the event that an osteocyte dies, the lacunar space is maintained up until the time that the packet of bone is removed, or removed and replaced. In this way an osteocyte leaves a "shallow grave" for the investigator to discover and analyze by the techniques summarized in Table 1 and discussed further below.

In the 1960's Frost described osteocyte loss in bones as evidenced by empty lacunae, which increased with the age of the patient [10]. Dunstan subsequently reported large scale osteocyte loss in some bone sites with aging such that only $20 \%$ of osteocytes remain alive in bones of an 80 year old patient [11-13]. When osteocytes die, the cellular material is dispersed, but in some cases this material is replaced with or translated into mineralized spheres that may coalesce to completely fill the lacuna space. This phenomenon was first 
identified by Frost and was named "micropetrosis" [10], and has been noted by others [14, 15]. While the derivation of the beads of mineralized material are unknown, there is a possibility that they are seeded by apoptotic cell remnants that are not cleared from the lacuna-canalicular system.

The presence of empty lacunae should be treated with caution since the 7 micrometer thick sections often used for histologic examination may not contain cell remnants after fixation related shrinkage has occurred. This is a particularly important consideration if the method of apoptosis detection relies on labeling cell nuclei that have a small volume for discovery. Moreover, some apoptotic osteocytes may also be lost during tissue processing because the cells have lost their anchorage to the surrounding lacunar wall [16]. On the other hand, the presence of cellular material in lacunae is not a measure of osteocyte viability since dead cells can be stained by a variety of standard and fluorescence-based dyes and contrast techniques. For these reasons absence of lactate dehydrogenase activity may provide a more accurate assessment of osteocyte death [1,11], but - like the presence of empty lacunae this approach cannot provide evidence of the mode of death.

More reliable determinations of osteocyte apoptosis have utilized morphological and biochemical changes that are in line with the classic apoptotic changes seen in other cell types. Cell shrinkage, nuclear condensation and apoptotic body formation have all been noted in osteocytes in situ [1], and apoptotic bodies have been noted in cell culture models [17] (Figure 1a,b). In contrast with apoptosis, death by necrosis is due mainly to loss of membrane integrity, and swelling of the cell to such an extent that it bursts (Figure 1c).

The diameter of osteocyte-derived apoptotic bodies is in the nanometer to the micrometer range [17]. Since the diameter of canaliculi range from 50 to $100 \mathrm{~nm}$ [18], it is possible that some of these particles travel long distances when dying cells vacate the system. Apoptotic bodies from cultured osteocytes also exhibit authentic membrane inversion such that phosphatidyl serine is externalized while retaining membrane integrity [17], both of which are characteristics of apoptotic cells. Apoptotic bodies are normally phagocytosed, and while macrophages do not have access to apoptotic osteocytes, osteoclasts do. However, the extent to which osteocyte-derived apoptotic bodies remain in the lacunar space, are distributed through the canalicular network, or are removed during osteoclastic bone resorption remains unknown.

The internucleosomal degradation of DNA that occurs during apoptosis results in the formation of DNA fragments comprising multiples of 180-200 base pairs that produce a characteristic DNA ladder upon gel electrophoresis. Apoptotic osteocyte DNA has been shown to fragment in this way while necrotic osteocyte DNA produces a smear following electrophoresis [19]. Histologic detection of fragmented DNA has facilitated quantification of apoptotic osteocytes. The increased number of free DNA ends can be visualized by attaching labeled nucleotides using the terminal deoxynucleotide transferase mediated dUTP nick-end labeling (TUNEL) procedure, or using the Klenow enzyme to perform in situ endlabeling (ISEL), also known as nick translation [1,20]. The most important difference is that TUNEL techniques will tend to greatly amplify the fragmentation signal whereas ISEL does this to a lesser extent, rendering it more specific. Identification of osteocytes with fragmented DNA has shown baseline levels of apoptosis of some $1 \%$ or below in cultured cells, and as high as $15 \%$ in bone from estrogen deficient women or rodents [19, 21, 22]. The proportion of cells labeled positive will relate to the number of apoptotic cells and the time it takes to clear the apoptotic material from the site of death. The slower clearance of osteocyte material from the lacuna canalicular system likely explains the higher levels of apoptosis seen in healthy bone relative to the number of apoptotic cells present in most other tissues. 
Immunostaining for the active form of caspase-3 is highly specific for detection of apoptotic osteocytes in situ [23] as shown in Figure 1d. In short-term experiments, inhibition of TUNEL or ISEL staining by administration of a synthetic inhibitor of caspase activity can be used to prove death by apoptosis as opposed to other regulated death programs. A variety of other methods are available for detecting apoptotic cells in vitro, including release of cytochrome $\mathrm{c}$ into the cytoplasm and externalization of phosphatidyl serine [24]. Using these methods, it is possible to use data from in vitro studies with osteocyte-like cells to infer induction of apoptotic osteocyte death in vivo, for example in response to excess glucocorticoids [25].

\section{Osteocyte apoptosis and the response of bone to load}

Recent discoveries show that regulation of osteocyte apoptosis by mechanical forces is an integral component of the adaptive response of bone to changes in load (Table 2). The relationship between osteocyte viability and mechanical strain follows a U-shaped curve. Skeletal unloading in rodents is associated with increased osteocyte apoptosis in both trabecular and cortical bone, and bone loss in both compartments [26, 27]. On the other hand, application of mechanical strain at levels that are sufficient to induce bone formation reduces the prevalence of apoptotic osteocytes. Thus, short periods of mechanical stimulation that resulted in peak compressive strains of 3000-4000 microstrain caused a $40 \%$ reduction in apoptotic osteocytes relative to untreated control limbs [26]. The generation of similar strains in human bone ex vivo resulted in similar reductions in osteocyte apoptosis, whereas unloading resulted in high levels of apoptosis [28].

In vitro studies of mechanical control of osteocyte apoptosis have pointed to the importance of fluid shear stress [29] and to the involvement of mitogen-activated protein kinases (MAPKs) in maintaining osteocyte viability [30]. Application of pulsatile fluid flow in osteocytic MLO-Y4 cultures stimulated Wnt signaling and inhibited apoptosis in a manner that was dependent on stimulation of nitric oxide synthesis [31, 32]. In vivo, osteocytic processes interact with the extracellular matrix via integrins that tether osteocytes to the canalicular wall. Thus, it has been proposed that movement of fluid in the canaliculi generates tension on the tethering elements, thereby stimulating integrin signaling [30,33]. Activation of integrins has been shown to prevent apoptosis in a variety of cell types [34].

Besides fluid flow, proteolysis of the extracellular collagenous matrix that lines the lacunacanalicular system may also provide survival signals to osteocytes as evidenced by the finding of increased osteocyte apoptosis in mice with collagenase-resistant type I collagen [35]. The identity of these signals is unknown. However, isolated murine osteocytes produce a variety of growth factors, some of which have anti-apoptotic properties, including fibroblast growth factor 1 , and transforming growth factor- $\beta 3$ [36]. Thus, it is possible that such anti-apoptotic factors are deposited in the extracellular matrix by osteocytes, and that they are released during collagenase-mediated remodeling of this matrix.

As in the case of unloading, application of strain of sufficient magnitude to produce microdamage is associated with increased osteocyte apoptosis. The microdamage comprises small cracks in the mineralized matrix that can coalesce to form larger lesions and eventually, overt fracture [37,38]. Microcracks have been shown to disrupt canalicular integrity resulting in ruptured dendritic processes [39]. This may result in disruption of fluid flow, as well as other conditions known to induce apoptosis including loss of nutrients, hypoxia, and detachment of osteocytes from extracellular matrix. Experiments generating strains of 8000 microstrain in ulnae of rodents demonstrated that the resulting microdamage preceded a dramatic increase in osteocyte apoptosis and a later influx of bone resorptive osteoclasts $[26,40]$. Schaffler and colleagues reported that apoptotic osteocytes were found 
in the immediate vicinity of the microcracks as evidenced by pyknotic nuclei, TUNEL staining, and immunostaining for active caspase-3 (Figure 1d) [41]. Moreover, osteocytes adjacent to damaged bone exhibited increased staining for the pro-apoptotic protein Bax, whereas cells 1-2 mm from the microcracks tend to express higher levels of the antiapoptotic protein Bcl-2 [42]. Administration of a synthetic pan-caspase inhibitor prevented the appearance of both apoptotic osteocytes and activation of osteoclastic bone resorption [41], supporting the contention that osteocyte apoptosis mediates the pro-osteoclastogenic process activated by fatigue damage.

\section{Osteocyte apoptosis and the stimulation of bone modeling and remodeling during growth and sex steroid deficiency}

Osteocyte apoptosis is elevated in bone with high rates of modeling or remodeling [1]. Thus, the prevalence of osteocyte apoptosis is high in human infant calvaria where the high osteoclastic resorption activity contributes to the modeling process by which these bones are shaped. Similarly, osteocyte apoptosis is high in osteophyte bone which exhibits rapid bone turnover. In contrast, osteocyte apoptosis is low in the adult iliac crest and femoral head, which have comparatively low remodeling.

In the ovariectomized rodent model of estrogen loss, osteocyte apoptosis increased dramatically over the 2 week post ovariectomy period of peak osteoclastic activity [21]. In a similar way, when estrogen levels were reduced by administration of gonadotropin-releasing hormone for the treatment of endometriosis in young women, increased osteocyte apoptosis accompanied large-scale trabecular bone loss at the iliac crest [19]. Ovariectomy or orchidectomy of mice also increased osteocyte apoptosis [22]. It would thus appear that sex steroids are fundamental to the survival of osteocytes in bone. In vitro studies demonstrated that estrogens activate MAPK-dependent anti-oxidant signaling via an extranuclear function of the estrogen receptor [43].

Recent experiments in rodents indicate that, as in the case of fatigue damage, osteocyte apoptosis is required for the local activation of endosteal resorption that occurs following loss of sex steroids [44]. The cortical bone of ovariectomized rats exhibits a 4-7-fold increase in the number of apoptotic osteocytes, as detected by active caspase- 3 immunostaining. Interestingly, the apoptotic osteocytes are mainly located in the posterior portion of the diaphyseal cortex, which contains the oldest osteocytes. There were fewer canalicular connections between these older osteocytes as compared to younger osteocytes in other portions of the diaphyseal cortex. Because of their age, these osteocytes may already be under stress, and perhaps more sensitive to the increase in reactive oxygen species caused by loss of estrogen $[43,45]$. Pharmacologic inhibition of caspase activity prevented both the increase in apoptotic osteocytes and the increase in endosteal bone resorption caused by ovariectomy. Thus, osteocyte apoptosis may activate resorption of the endosteal surface of the cortex, and thereby contribute to the cortical thinning caused by estrogen deficiency.

\section{Osteocyte apoptosis and the regulation of osteocyte-derived RANKL}

The evidence linking osteocyte apoptosis to increased local bone resorption suggests that dying osteocytes elaborate a pro-osteoclastogenic signal. This notion is supported by the finding that a single injection of diphtheria toxin to mice with osteocyte-specific expression of the diphtheria toxin receptor induced apoptosis in cancellous and cortical osteocytes. This effect was associated with increased RANKL expression and the development of intracortical remodeling and porosity within 7 days [46]. Moreover, unloading failed to induce bone loss in these osteocyte-ablated mice. Importantly, O'Brien and colleagues 
showed that deletion of the RANKL gene specifically in osteocytes using the dentin matrix protein-1 (DMP-1) promoter prevented the bone loss caused by unloading, thus implicating osteocytes themselves as the source of the RANKL needed for the local generation of osteoclasts in this model [47].

Although it is conceivable that apoptotic osteocytes produce RANKL, it seems more likely that they signal other osteocytes to do so. Indeed, this was shown to be the case in the fatigue damage model. Apoptotic osteocytes juxtaposed to microcracks did not express detectable RANKL as determined by immunostaining [48]. Instead, RANKL was expressed by viable osteocytes located $100-300 \mu \mathrm{m}$ from the microcracks, and the level of its expression progressively declined beyond this location. On the other hand, OPG immunostaining was low in apoptotic osteocytes, and progressively increased in nonapoptotic cells greater than $200 \mu \mathrm{m}$ from microcracks. Bone remodeling requires capillaries that act as a conduit for the delivery of osteoclast progenitors from the circulation to the site of bone resorption [49]. As in the case of RANKL, apoptotic osteocytes induced by fatigue damage did not express VEGF, but neighboring viable caspase-negative osteocytes did [48]. Thus, the local increase in osteoclasts associated with osteocyte death in the fatigue damage model is the result of loss of OPG-producing osteocytes due to cell death, and increased production of RANKL and VEGF by neighboring viable osteocytes.

These findings provide the basis for a general model for the regulation of local bone remodeling by apoptotic osteocytes, regardless of whether apoptosis is caused by unloading, fatigue damage, ovariectomy, or signals that shape bone during modeling. Moreover, they imply that apoptotic osteocytes release factors that instruct neighboring osteocytes to produce RANKL, VEGF and perhaps other cytokines that influence osteoclast differentiation and bone remodeling.

Short-term prevention of osteocyte apoptosis with a pharmacologic caspase inhibitor attenuated the increase in RANKL caused by fatigue damage. Conversely, recent studies of ours showed that long-term prevention of osteocyte apoptosis by deletion of the proapoptotic proteins Bak and Bax greatly magnified the age-related increase in intra-cortical porosity in mice as a result of increased production of RANKL and VEGF [50]. These changes were associated with an increase in the number of dysmorphic cortical osteocytes. By preventing apoptosis, the lifespan of cortical osteocytes was increased beyond their intrinsic limit, thereby making them older and perhaps more sensitive to the effects of agerelated insults as compared to the same population of cells in the control mice. As a result, the Bak/Bax-deficient osteocytes were more likely to accumulate damage by the oxidative stress and growth factor scarcity that is associated with old age [51, 52]. These findings raise the possibility that distress signals produced by old and/or dysfunctional osteocytes in cortical bone increase the local synthesis of RANKL and VEGF, and are therefore the culprits of the intracortical porosity seen in elderly humans [53, 54].

\section{Regulation of RANKL by signals produced by apoptotic osteocytes}

The evidence that apoptotic osteocytes provide signals that alter the biosynthetic activity of neighboring osteocytes fits with an emerging concept that apoptotic cells promote tissue regeneration. For example, apoptosis is required for tissue regeneration in Hydra and Drosophila via activation of Wnt signaling [55, 56]; and for prostaglandin-dependent skin wound healing, as well as liver regeneration, in mice [57]. Robling and colleagues have shown that, like many other cell types undergoing apoptosis or necrosis, osteocyte-like MLO-Y4 cells release high mobility group box 1 (HMGB1) protein [58, 59]. HMGB1 is ubiquitously expressed and ordinarily acts in the nucleus to regulate gene expression. However, when released by dying cells, HMGB1 binds to receptor for advanced glycation 
end products, and to toll-like receptors, to increase the expression of numerous inflammatory cytokines. HMGB1 stimulates the synthesis of RANKL, TNFa, and IL6, but inhibits the production of OPG, by bone marrow-derived stromal cells. It is thus reasonable to assume that HMGB1 has similar effects on osteocytes.

Apoptotic bodies produced during the last stages of apoptosis represent another potential means of communication with neighboring viable cells. In soft tissues, phagocytosis of apoptotic bodies by macrophages activates the synthesis of cytokines such as VEGF [60]. Moreover, apoptotic bodies derived from dying endothelial cells are taken up by vascular cells, resulting in the production of chemokines [61]. Apoptotic bodies generated from apoptotic MLO-Y4 cells, or apoptotic osteocyte-like cells derived from neonatal calvaria, range from 20 to $1000 \mathrm{~nm}$ in diameter. If the same is true in vivo, they would be capable of delivering a signal to neighboring osteocytes via the $700 \mathrm{~nm}$ diameter canaliculi that had been vacated due to cell death. However, comparatively few apoptotic bodies could traverse the 50-100 nm width of fluid space that surrounds the dendritic processes of viable osteocytes [62]. Thus the majority of apoptotic body interactions might be with viable osteocytes in the immediate vicinity. Interestingly, apoptotic bodies derived from MLO-Y4 cells stimulated osteoclast differentiation in a RANKL-independent manner both in vitro and in vivo. However, apoptotic bodies isolated from dying osteoblastic cells were unable to do so [17], suggesting the existence of one or more osteocyte-specific osteoclastogenic factors.

\section{Consequences of glucocorticoid-induced osteocyte apoptosis}

Osteocyte apoptosis has been recognized as a feature of glucocorticoid-induced osteoporosis for more than a decade. Recent studies have provided clues about the importance of apoptotic osteocytes in this condition and the relationship to fracture. Loss of bone mineral density (BMD) in glucocorticoid-induced osteoporosis is biphasic; rapid (6-12\%) within the first year and then slower ( 3\% yearly) thereafter [63]. However, the risk of fracture escalates by as much as $75 \%$ within the first 3 months of therapy, typically before a significant decline in BMD, suggesting adverse effects of glucocorticoids on bone that are not captured by bone densitometry [64]. Histomorphometric studies in patients and animals with glucocorticoid-induced osteoporosis consistently show decreased osteoblasts and an increased prevalence of osteoblast and osteocyte apoptosis, as detected by ISEL staining (Fig. 2) $[65,66]$. In contrast to the effect of glucocorticoids to induce apoptosis of osteoblasts and osteocytes, these drugs directly prolong osteoclast life span [67]. This is based on the evidence that blockade of glucocorticoid action on osteoclasts in cancellous bone using the tartrate-resistant acid phosphatase (TRAP) promoter and transgenic expression of $11 \beta$-hydroxysteroid dehydrogenase type 2 (11 $\beta$-HSD2), an enzyme that inactivates glucocorticoids in a pre-receptor fashion, attenuates the glucocorticoid-induced increase in osteoclasts [68]. This occurs even though glucocorticoid-induced osteoblast apoptosis and presumably osteocyte apoptosis were unabated. Therefore, unlike the proosteoclastogenic signaling resulting from osteocyte apoptosis due to loss of sex steroids, fatigue damage, or unloading, glucocorticoid-induced osteocyte apoptosis may not be involved in increasing osteoclast number. The lack of osteoclastogenic signaling from the apoptotic osteocytes could be due to the effect of glucocorticoids to blunt cytokine synthesis. In line with this contention, administration of prednisolone for 7 days did not affect either RANKL or OPG expression in murine lumbar vertebrae [68].

Glucocorticoid excess also causes a reduction in bone blood flow and the water present in the skeletal vasculature and lacunar-canalicular system [69]. Water represents at least 25\% of the wet weight of bone and confers to bone much of its unique strength and resilience by reducing stresses during dynamic loading [70]. Of the total volume of water in bone, 
approximately $90 \%$ resides in the vasculature, marrow, and lacunar-canalicular system that surround the intricate network of osteocytes [71].

The contribution of osteoblast and osteocyte apoptosis to the adverse effects of glucocorticoids on the vascularity of bone was shown by blockade of glucocorticoid action on these cells using the OG2 osteocalcin promoter driving $11 \beta$-HSD2. In a quantitative angiogenesis assay, prednisone decreased the vascular sprouting in cultures of wild-type metatarsals by one-third, but this decrease was prevented in the metatarsals taken from the transgenic mice. Adult transgenic mice were also protected from glucocorticoid-induced osteoblast and osteocyte apoptosis, and reduced osteoid area, bone formation rate, skeletal vascularity, fluid in the lacunar-canalicular system, and bone strength [25]. Taken together, these findings suggest that the adverse effects of glucocorticoids on bone vascularity and strength are due to direct effects on osteoblasts, osteocytes, or both.

Blockade of glucocorticoid action on osteocytes via 11 $\beta$-HSD2 expression under control of a DMP-1 promoter distinguished between these possibilities. Osteocyte-specific activity of this promoter fragment has been demonstrated previously in DMP1-GFP mice, which express GFP in osteocytes but not in osteoblasts [72]. Prednisone caused a decrease in vascular sprout area and vessel length in the metatarsals taken from the wild-type animals but these changes were prevented in the metatarsals obtained from the DMP-1-11 $\beta$-HSD2 transgenic mice. These results strongly suggest that excess glucocorticoids adversely affect bone vascularity due to direct effects on osteocytes [73]. Thus, glucocorticoid-induced osteocyte apoptosis and decrements in bone vascularity could account for the loss of bone strength that occurs before loss of BMD and the observed mismatch between BMD and fracture risk in patients with glucocorticoid-induced osteoporosis [64, 69, 74].

Accumulation of apoptotic osteocytes may also contribute to glucocorticoid-induced collapse of the femoral head, a disorder known as osteonecrosis of the hip. This crippling disorder often leads to total hip replacement and develops in 9-40\% of patients receiving long term systemic glucocorticoid therapy as well as after intraarticular injection of these drugs [75]. The femoral head is particularly at risk due to the huge load transferred to the hip joint and to the limited blood supply [76]. Abundant apoptotic osteocytes have been identified in sections of whole femoral heads obtained during total hip replacement for glucocorticoid-induced osteonecrosis, whereas apoptotic bone cells were uncommon with alcohol-induced osteonecrosis and post-traumatic osteonecrosis (Fig 3) [77, 78]. In addition, cell swelling and inflammation typical of necrosis did not occur with glucocorticoids. A prevalence map of osteocyte apoptosis made from sections of the femoral head showed that osteocyte apoptosis was most prevalent adjacent to the subchondral crescent and fracture cleft and decreased as the examination progressed more distally. Osteocyte apoptosis was anatomically juxtaposed to the osteonecrotic fracture. Glucocorticoid-induced osteonecrosis is a misnomer: the so-called glucocorticoid-induced "osteonecrosis" is actually osteocyte apoptosis. Apoptotic osteocytes with pyknotic nuclei have also been identified in femora and humeri of glucocorticoid-treated rabbits [79].

Empty osteocytic lacunae have been thought to be the cardinal sign of osteonecrosis [80], but it is also possible that apoptotic osteocytes were lost during tissue processing as mentioned earlier. Bone specimens from patients and animals with glucocorticoid-induced osteoporosis or osteonecrosis rarely show empty osteocytic lacunae [65, 77-79]. With glucocorticoid treatment, rapid removal of the apoptotic osteocytes is unlikely because of the reduced bone turnover caused by glucocorticoid excess, anatomic isolation of osteocytes from phagocytes, and extensive degradation of the DNA fragments that would be required for disposal through the canalicular system. 
The apoptotic osteocytes in glucocorticoid-induced osteonecrosis may interfere with endothelial angiogenesis and the production and action of VEGF [69]. In addition, VEGF production by osteoblasts and osteocytes has been shown to couple bone formation and angiogenesis [81]. In line with this, osteonecrosis of the femoral head has been reported without glucocorticoid therapy in cancer patients receiving bevacizumab or sunitinib, agents used to target the VEGF pathway [82]. Thus, glucocorticoid excess may further aggravate the limited arterial supply of the femoral head, which is already restricted to a minute and variable contribution via the ligamentum teres [83] with the remainder primarily coming from the medial and lateral femoral circumflex arteries without effective collateral circulation [84]. Furthermore, the femoral head is covered by a layer of cartilage devoid of nutrient arteries. Glucocorticoid-induced osteocyte apoptosis, a cumulative and unrepairable defect, could uniquely disrupt the osteocyte network, decrease canalicular water, reduce bone strength, and thus start the inexorable sequence of events leading to deformity of the femoral head.

However, attenuation of glucocorticoid-induced osteocyte apoptosis can be accomplished. Intermittent administration of parathyroid hormone (PTH) decreases the prevalence of osteocyte apoptosis in mice and addition of PTH to MLO-Y4 cells ameliorates the proapoptotic effect of etoposide or dexamethasone [85]. Daily injections of PTH to adult mice receiving prednisolone prevented the increase in the prevalence of osteoblast and osteocyte apoptosis and the decrease in osteoblasts number, bone formation, and strength [86]. Further evidence for a contribution of osteocyte viability to strength was indicated by the inverse relationship between the prevalence of osteocyte apoptosis and vertebral compression strength. Additional support for this relationship was supplied by the unexpected finding that administration of the RANKL antagonist OPG prevented the glucocorticoid-induced increase in the prevalence of osteocyte apoptosis and reduction in solute transport from the systemic circulation to the osteocyte-lacunar-canalicular network as well as contributed to the preservation of bone strength [87]. However, the mechanism underlying the anti-apoptotic effect of OPG is unknown.

\section{Conclusions and future directions}

Current evidence supports a model whereby the apoptotic demise of osteocytes instructs neighboring viable osteocytes to synthesize cytokines like RANKL and VEGF, which then recruit osteoclasts to remove the dead cells and initiate the remodeling of the surrounding matrix. Glucocorticoid-induced apoptosis of osteocytes is an exception because the reduction in bone turnover that accompanies glucocorticoid excess prevents remodeling. Elucidation of the RANKL- and VEGF-inducing factors produced by apoptotic osteocytes is clearly an urgent research goal, as is the transcriptional response of osteocytes to these factors. Whether osteocytes die by non-apoptotic mechanisms under physiologic or pathologic conditions also requires further investigation.

\section{Acknowledgments}

This work was supported by grants from the Biomedical Laboratory Research and Development Service of the Veterans Affairs Office of Research and Development to R.L.J. (I01 BX000514) and R.S.W. (I01 BX000436); by the National Institutes of Health (P01 AG013918); and by Tobacco Settlement Funds provided by the UAMS College of Medicine.

\section{Reference List}

1. Noble BS, Stevens H, Loveridge N, Reeve J. Identification of apoptotic changes in osteocytes in normal and pathological human bone. Bone. 1997; 20:273-82. [PubMed: 9071479] 
2. Kroemer G, Galluzzi L, Brenner C. Mitochondrial membrane permeabilization in cell death. Phys Rev. 2007; 87:99-163.

3. Dewson G, Ma S, Frederick P, Hockings C, Tan I, Kratina T, et al. Bax dimerizes via a symmetric BH3: groove interface during apoptosis. Cell Death Differ. 2011

4. Kumar S. Caspase function in programmed cell death. Cell Death Differ. 2006; 14:32-43. [PubMed: 17082813]

5. Fischer U, Janicke RU, Schulze-Osthoff K. Many cuts to ruin: a comprehensive update of caspase substrates. Cell Death Differ. 2003; 10:76-100. [PubMed: 12655297]

6. Galluzzi L, Vitale I, Abrams JM, Alnemri ES, Baehrecke EH, Blagosklonny MV, et al. Molecular definitions of cell death subroutines: recommendations of the Nomenclature Committee on Cell Death 2012. Cell Death Differ. 2012; 19:107-20. [PubMed: 21760595]

7. Vanlangenakker N, Vanden Berghe T, Vandenabeele P. Many stimuli pull the necrotic trigger, an overview. Cell Death Differ. 2012; 19:75-86. [PubMed: 22075985]

8. Jilka, RL.; Bellido, T.; Almeida, M.; Plotkin, LI.; O’Brien, C.; Weinstein, RS., et al. Apoptosis of Bone Cells. In: Bilezikian, JP.; Raisz, LG.; Martin, T., editors. Principles of Bone Biology. Academic Press; 2008. p. 235-59.

9. Jilka RL, Weinstein RS, Parfitt AM, Manolagas SC. Quantifying osteoblast and osteocyte apoptosis: challenges and rewards. J Bone Miner Res. 2007; 22:1492-501. [PubMed: 17542686]

10. Frost HM. In vivo osteocyte death. J Bone Joint Surg. 1960; 42A:138-43. [PubMed: 13849861]

11. Dunstan CR, Evans RA, Hills E, Wong SY, Higgs RJ. Bone death in hip fracture in the elderly. Calcif Tissue Int. 1990; 47:270-5. [PubMed: 2257519]

12. Dunstan CR, Somers NM, Evans RA. Osteocyte death and hip fracture. Calcif Tissue Int. 1993; 53 (Suppl 1):S113-S116. [PubMed: 8275364]

13. Wong SY, Evans RA, Needs C, Dunstan CR, Hills E, Garvan J. The pathogenesis of osteoarthritis of the hip. Evidence for primary osteocyte death. Clin Orthop. 1987:305-12. [PubMed: 3791756]

14. Boyde A, Hendel P, Hendel R, Maconnachie E, Jones SJ. Human cranial bone structure and the healing of cranial bone grafts: a study using backscattered electron imaging and confocal microscopy. Anat Embryol (Berl). 1990; 181:235-51. [PubMed: 2337245]

15. Busse B, Djonic D, Milovanovic P, Hahn M, Puschel K, Ritchie RO, et al. Decrease in the osteocyte lacunar density accompanied by hypermineralized lacunar occlusion reveals failure and delay of remodeling in aged human bone. Aging Cell. 2010; 9:1065-75. [PubMed: 20874757]

16. Jilka RL, Weinstein RS, Bellido T, Parfitt AM, Manolagas SC. Osteoblast programmed cell death (apoptosis): modulation by growth factors and cytokines. J Bone Miner Res. 1998; 13:793-802. [PubMed: 9610743]

17. Kogianni G, Mann V, Noble BS. Apoptotic bodies convey activity capable of initiating osteoclastogenesis and localized bone destruction. J Bone Miner Res. 2008; 23:915-27. [PubMed: 18435576]

18. Su M, Jiang H, Zhang P, Liu Y, Wang E, Hsu A, et al. Knee-loading modality drives molecular transport in mouse femur. Ann Biomed Eng. 2006; 34:1600-6. [PubMed: 17029032]

19. Tomkinson A, Reeve J, Shaw RW, Noble BS. The death of osteocytes via apoptosis accompanies estrogen withdrawal in human bone. Journal of Clinical Endocrinology and Metabolism. 1997; 82:3128-35. [PubMed: 9284757]

20. Riahi S, Noble B. Techniques for the study of apoptosis in bone. Methods Mol Biol. 2012; 816:335-49. [PubMed: 22130939]

21. Tomkinson A, Gevers EF, Wit JM, Reeve J, Noble BS. The role of estrogen in the control of rat osteocyte apoptosis. J Bone Miner Res. 1998; 13:1243-50. [PubMed: 9718192]

22. Almeida M, Han L, Martin-Millan M, Plotkin LI, Stewart SA, Roberson PK, et al. Skeletal involution by age-associated oxidative stress and its acceleration by loss of sex steroids. J Biol Chem. 2007; 282:27285-97. [PubMed: 17623659]

23. Follet H, Li J, Phipps RJ, Hui S, Condon K, Burr DB. Risedronate and alendronate suppress osteocyte apoptosis following cyclic fatigue loading. Bone. 2007; 40:1172-7. [PubMed: 17240209] 
24. Elmore S. Apoptosis: A Review of Programmed Cell Death. Toxicologic Pathology. 2007; 35:495-516. [PubMed: 17562483]

25. O'Brien CA, Jia D, Plotkin LI, Bellido T, Powers CC, Stewart SA, et al. Glucocorticoids act directly on osteoblasts and osteocytes to induce their apoptosis and reduce bone formation and strength. Endocrinology. 2004; 145:1835-41. [PubMed: 14691012]

26. Noble BS, Peet N, Stevens HY, Brabbs A, Mosley JR, Reilly GC, et al. Mechanical loading: biphasic osteocyte survival and targeting of osteoclasts for bone destruction in rat cortical bone. Am J Physiol Cell Physiol. 2003; 284:C934-C943. [PubMed: 12477665]

27. Aguirre JI, Plotkin LI, Stewart SA, Weinstein RS, Parfitt AM, Manolagas SC, et al. Osteocyte apoptosis is induced by weightlessness in mice and precedes osteoclast recruitment and bone loss. J Bone Miner Res. 2006; 21:605-15. [PubMed: 16598381]

28. Mann V, Huber C, Kogianni G, Jones D, Noble B. The influence of mechanical stimulation on osteocyte apoptosis and bone viability in human trabecular bone. J Musculoskelet Neuronal Interact. 2006; 6:408-17. [PubMed: 17185839]

29. Bakker A, Klein-Nulend J, Burger E. Shear stress inhibits while disuse promotes osteocyte apoptosis. Biochemical and Biophysical Research Communications. 2004; 320:1163-8. [PubMed: 15249211]

30. Plotkin LI, Mathov I, Aguirre JI, Parfitt AM, Manolagas SC, Bellido T. Mechanical stimulation prevents osteocyte apoptosis: requirement of integrins, Src kinases, and ERKs. Am J Physiol. 2005; 289:C633-C643.

31. Santos A, Bakker AD, Zandieh-Doulabi B, Semeins CM, Klein-Nulend J. Pulsating fluid flow modulates gene expression of proteins involved in Wnt signaling pathways in osteocytes. J Orthop Res. 2009; 27:1280-7. [PubMed: 19353691]

32. Tan SD, Bakker AD, Semeins CM, Kuijpers-Jagtman AM, Klein-Nulend J. Inhibition of osteocyte apoptosis by fluid flow is mediated by nitric oxide. Biochem Biophys Res Commun. 2008; 369:1150-4. [PubMed: 18339304]

33. Wang Y, McNamara LM, Schaffler MB, Weinbaum S. A model for the role of integrins in flow induced mechanotransduction in osteocytes. Proceedings of the National Academy of Sciences U S A. 2007; 104:15941-6.

34. Stupack DG, Cheresh DA. Get a ligand, get a life: integrins, signaling and cell survival. J Cell Sci. 2002; 115:3729-38. [PubMed: 12235283]

35. Zhao W, Byrne MH, Boyce BF, Krane SM. Bone resorption induced by parathyroid hormone is strikingly diminished in collagenase-resistant mutant mice. J Clin Invest. 1999; 103:517-24. [PubMed: 10021460]

36. Paic F, Igwe JC, Nori R, Kronenberg MS, Franceschetti T, Harrington P, et al. Identification of differentially expressed genes between osteoblasts and osteocytes. Bone. 2009; 45:682-92. [PubMed: 19539797]

37. Frost HM. Presence of microscopic cracks in vivo in bone. Henry Ford Hospital Med Bull. 1960; 8:25-35.

38. Reilly GC, Currey JD. The effects of damage and microcracking on the impact strength of bone. J Biomech. 2000; 33:337-43. [PubMed: 10673117]

39. Hazenberg JG, Freeley M, Foran E, Lee TC, Taylor D. Microdamage: a cell transducing mechanism based on ruptured osteocyte processes. J Biomech. 2006; 39:2096-103. [PubMed: 16112124]

40. Verborgt O, Gibson GJ, Schaffler MB. Loss of osteocyte integrity in association with microdamage and bone remodeling after fatigue in vivo. J Bone Miner Res. 2000; 15:60-7. [PubMed: 10646115]

41. Cardoso L, Herman BC, Verborgt O, Laudier D, Majeska RJ, Schaffler MB. Osteocyte apoptosis controls activation of intracortical resorption in response to bone fatigue. J Bone Miner Res. 2009; 24:597-605. [PubMed: 19049324]

42. Verborgt O, Tatton NA, Majeska RJ, Schaffler MB. Spatial distribution of Bax and Bcl-2 in osteocytes after bone fatigue: complementary roles in bone remodeling regulation? J Bone Miner Res. 2002; 17:907-14. [PubMed: 12009022] 
43. Almeida M, Han L, Ambrogini E, Bartell SM, Manolagas SC. Oxidative stress stimulates apoptosis and activated NF-kB in osteoblastic cells via a $\mathrm{PKC} \beta / \mathrm{p} 66^{\text {shc }}$ siganaling cascade: counter regulation by estrogens or androgens. Mol Endocrinol. 2010; 24:2030-7. [PubMed: 20685851]

44. Emerton KB, Hu B, Woo AA, Sinofsky A, Hernandez C, Majeska RJ, et al. Osteocyte apoptosis and control of bone resorption following ovariectomy in mice. Bone. 2010; 46:577-83. [PubMed: 19925896]

45. Almeida M, Han L, Martin-Millan M, Plotkin LI, Stewart SA, Roberson PK, et al. Skeletal involution by age-associated oxidative stress and its accleration by loss of sex steroids. J Biol Chem. 2007; 282:27285-97. [PubMed: 17623659]

46. Tatsumi S, Ishii K, Amizuka N, Li M, Kobayashi T, Kohno K, et al. Targeted ablation of osteocytes induces osteoporosis with defective mechanotransduction. Cell Metab. 2007; 5:464-75. [PubMed: 17550781]

47. Xiong J, Onal M, Jilka RL, Weinstein RS, Manolagas SC, O’Brien CA. Matrix-embedded cells control osteoclast formation. Nat Med. 2011; 17:1235-41. [PubMed: 21909103]

48. Kennedy OD, Herman BC, Laudier DM, Majeska RJ, Sun HB, Schaffler MB. Activation of resorption in fatigue-loaded bone involves both apoptosis and active pro-osteoclastogenic signaling by distinct osteocyte populations. Bone. 2012; 50:1115-22. [PubMed: 22342796]

49. Andersen TL, Sondergaard TE, Skorzynska KE, Dagnaes-Hansen F, Plesner TL, Hauge EM, et al. A physical mechanism for coupling bone resorption and formation in adult human bone. Am $\mathrm{J}$ Pathol. 2009; 174:239-47. [PubMed: 19095960]

50. Jilka R, DeLoose A, Climer L, Bonewald L, Weinstein R, O’Brien C, et al. Dysfunctional osteocytes increase RANKL and promote cortical pore formation in their vicinity: a mechanistic explanation for the development of cortical porosity with age. J Bone Miner Res. 2012; 27:S348.

51. Manolagas SC, Parfitt AM. What old means to bone. Trends in Endocrinology \& Metabolism. 2010; 21:369-74. [PubMed: 20223679]

52. Xian L, Wu X, Pang L, Lou M, Rosen CJ, Qiu T, et al. Matrix IGF-1 maintains bone mass by activation of mTOR in mesenchymal stem cells. Nat Med. 2012; 18:1095-101. [PubMed: 22729283]

53. Zebaze RM, Ghasem-Zadeh A, Bohte A, Iuliano-Burns S, Mirams M, Price RI, et al. Intracortical remodelling and porosity in the distal radius and post-mortem femurs of women: a cross-sectional study. Lancet. 2010; 375:1729-36. [PubMed: 20472174]

54. Nicks KM, Amin S, Atkinson EJ, Riggs BL, Melton LJ III, Khosla S. Relationship of age to bone microstructure independent of areal bone mineral density. J Bone Miner Res. 2012; 27:637-44. [PubMed: 22095490]

55. Galliot B, Chera S. The Hydra model: disclosing an apoptosis-driven generator of Wnt-based regeneration. Trends Cell Biol. 2010; 20:514-23. [PubMed: 20691596]

56. Morata G, Shlevkov E, Perez-Garijo A. Mitogenic signaling from apoptotic cells in Drosophila. Development, Growth \& Differentiation. 2011; 53:168-76.

57. Li F, Huang Q, Chen J, Peng Y, Roop DR, Bedford JS, et al. Apoptotic cells activate the "phoenix rising" pathway to promote wound healing and tissue regeneration. Sci Signal. 2010; 3:ra13. [PubMed: 20179271]

58. Yang J, Shah R, Robling AG, Templeton E, Yang H, Tracey KJ, et al. HMGB1 is a bone-active cytokine. J Cell Physiol. 2008; 214:730-9. [PubMed: 17786958]

59. Bidwell JP, Yang J, Robling AG. Is HMGB1 an osteocyte alarmin? J Cell Biochem. 2008; 103:1671-80. [PubMed: 17948903]

60. Golpon HA, Fadok VA, Taraseviciene-Stewart L, Scerbavicius R, Sauer C, Welte T, et al. Life after corpse engulfment: phagocytosis of apoptotic cells leads to VEGF secretion and cell growth. The FASEB Journal. 2004

61. Zernecke A, Bidzhekov K, Noels H, Shagdarsuren E, Gan L, Denecke B, et al. Delivery of MicroRNA-126 by Apoptotic Bodies Induces CXCL12-Dependent Vascular Protection. Sci Signal. 2009; 2:ra81. [PubMed: 19996457]

62. You LD, Weinbaum S, Cowin SC, Schaffler MB. Ultrastructure of the osteocyte process and its pericellular matrix. Anat Rec. 2004; 278A:505-13. 
63. LoCascio V, Bonucci E, Imbimbo B, Ballanti P, Adami S, Milani S, et al. Bone loss in response to long-term glucocorticoid therapy. Bone Miner. 1990; 8:39-51. [PubMed: 2306553]

64. Weinstein RS. Clinical practice. Glucocorticoid-induced bone disease. N Engl J Med. 2011; 365:62-70. [PubMed: 21732837]

65. Weinstein RS, Jilka RL, Parfitt AM, Manolagas SC. Inhibition of osteoblastogenesis and promotion of apoptosis of osteoblasts and osteocytes by glucocorticoids: potential mechanisms of their deleterious effects on bone. J Clin Invest. 1998; 102:274-82. [PubMed: 9664068]

66. Adler, RA.; Curtis, JR.; Saag, K.; Weinstein, RS. Glucocorticoid-induced osteoporosis. In: Marcus, R.; Feldman, D.; Nelsen, DA.; Rosen, CJ., editors. Osteoporosis. San Diego, CA: ElsevierAcademic Press; 2008. p. 1135-66.

67. Weinstein RS, Chen JR, Powers CC, Stewart SA, Landes RD, Bellido T, et al. Promotion of osteoclast survival and antagonism of bisphosphonate-induced osteoclast apoptosis by glucocorticoids. J Clin Invest. 2002; 109:1041-8. [PubMed: 11956241]

68. Jia D, O'Brien CA, Stewart SA, Manolagas SC, Weinstein RS. Glucocorticoids act directly on osteoclasts to increase their life span and reduce bone density. Endocrinology. 2006; 147:5592-9. [PubMed: 16935844]

69. Weinstein RS, Wan C, Liu Q, Wang Y, Almeida M, O'Brien CA, et al. Endogenous glucocorticoids decrease skeletal angiogenesis, vascularity, hydration, and strength in aged mice. Aging Cell. 2010; 9:147-61. [PubMed: 20047574]

70. Wilson EE, Awonusi A, Morris MD, Kohn DH, Tecklenburg MM, Beck LW. Three structural roles for water in bone observed by solid-state NMR. Biophys J. 2006; 90:3722-31. [PubMed: 16500963]

71. Timmins PA, Wall JC. Bone water. Calcif Tissue Res. 1977; 23:1-5. [PubMed: 890540]

72. Yang W, Lu Y, Kalajzic I, Guo D, Harris MA, Gluhak-Heinrich J, et al. Dentin matrix protein 1 gene cis-regulation: use in osteocytes to characterize local responses to mechanical loading in vitro and in vivo. J Biol Chem. 2005; 280:20680-90. [PubMed: 15728181]

73. Weinstein RS, Hogan EA, O'Brien CA, Manolagas SC. Glucocorticoids act directly on osteocytes to reduce bone vascularity and strength. J Bone Miner Res. 2012; 27:Sxxx.

74. Seeman E, Delmas PD. Bone Quality -- The Material and Structural Basis of Bone Strength and Fragility. N Engl J Med. 2006; 354:2250-61. [PubMed: 16723616]

75. Weinstein RS. Glucocorticoid-induced osteonecrosis. Endocrine. 2012; 41:183-90. [PubMed: 22169965]

76. Heimann WG, Freiberger RH. Avascular Necrosis of the Femoral and Humeral Heads after HighDosage Corticosteroid Therapy. N Engl J Med. 1960; 263:672-5. [PubMed: 13712871]

77. Weinstein RS, Nicholas RW, Manolagas SC. Apoptosis of osteocytes in glucocorticoid-induced osteonecrosis of the hip. J Clin Endocrinol Metab. 2000; 85:2907-12. [PubMed: 10946902]

78. Youm YS, Lee SY, Lee SH. Apoptosis in the osteonecrosis of the femoral head. Clin Orthop Surg. 2010; 2:250-5. [PubMed: 21119943]

79. Eberhardt AW, Yeager-Jones A, Blair HC. Regional trabecular bone matrix degeneration and osteocyte death in femora of glucocorticoid- treated rabbits. Endocrinology. 2001; 142:1333-40. [PubMed: 11181552]

80. Mankin HJ. Nontraumatic necrosis of bone (osteonecrosis). N Engl J Med. 1992; 326:1473-9. [PubMed: 1574093]

81. Wang Y, Wan C, Deng L, Liu X, Cao X, Gilbert SR, et al. The hypoxia-inducible factor a pathway couples angiogenesis to osteogenesis during skeletal development. J Clin Invest. 2007; 117:1616-26. [PubMed: 17549257]

82. Mir O, Coriat R, Gregory T, Ropert S, Billemont B, Goldwasser F. Avascular necrosis of the femoral head: a rare class-effect of anti-VEGF agents. Invest New Drugs. 2011; 29:716-8. [PubMed: 20177735]

83. Bardakos NV, Villar RN. The ligamentum teres of the adult hip. J Bone Joint Surg Br. 2009; 91:815. [PubMed: 19091998]

84. Johnson EO, Soultanis K, Soucacos PN. Vascular anatomy and microcirculation of skeletal zones vulnerable to osteonecrosis: vascularization of the femoral head. Orthop Clin North Am. 2004; 35:285-91. viii. [PubMed: 15271536] 
85. Jilka RL, Weinstein RS, Bellido T, Roberson P, Parfitt AM, Manolagas SC. Increased bone formation by prevention of osteoblast apoptosis with parathyroid hormone. J Clin Invest. 1999; 104:439-46. [PubMed: 10449436]

86. Weinstein RS, Jilka RL, Almeida M, Roberson PK, Manolagas SC. Intermittent parathyroid hormone administration counteracts the adverse effects of glucocorticoids on osteoblast and osteocyte viability, bone formation, and strength in mice. Endocrinology. 2010; 151:2641-9. [PubMed: 20410195]

87. Weinstein RS, O’Brien CA, Almeida M, Zhao H, Roberson PK, Jilka RL, et al. Osteoprotegerin Prevents Glucocorticoid-Induced Osteocyte Apoptosis in Mice. Endocrinology. 2011; 152:332331. [PubMed: 21771887] 

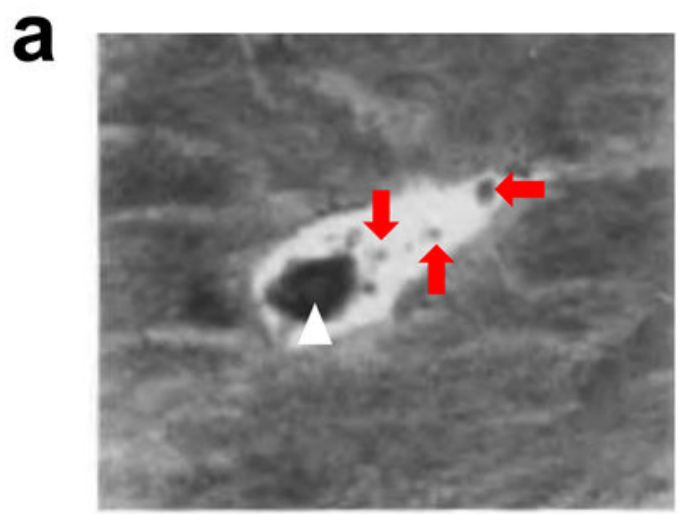

b
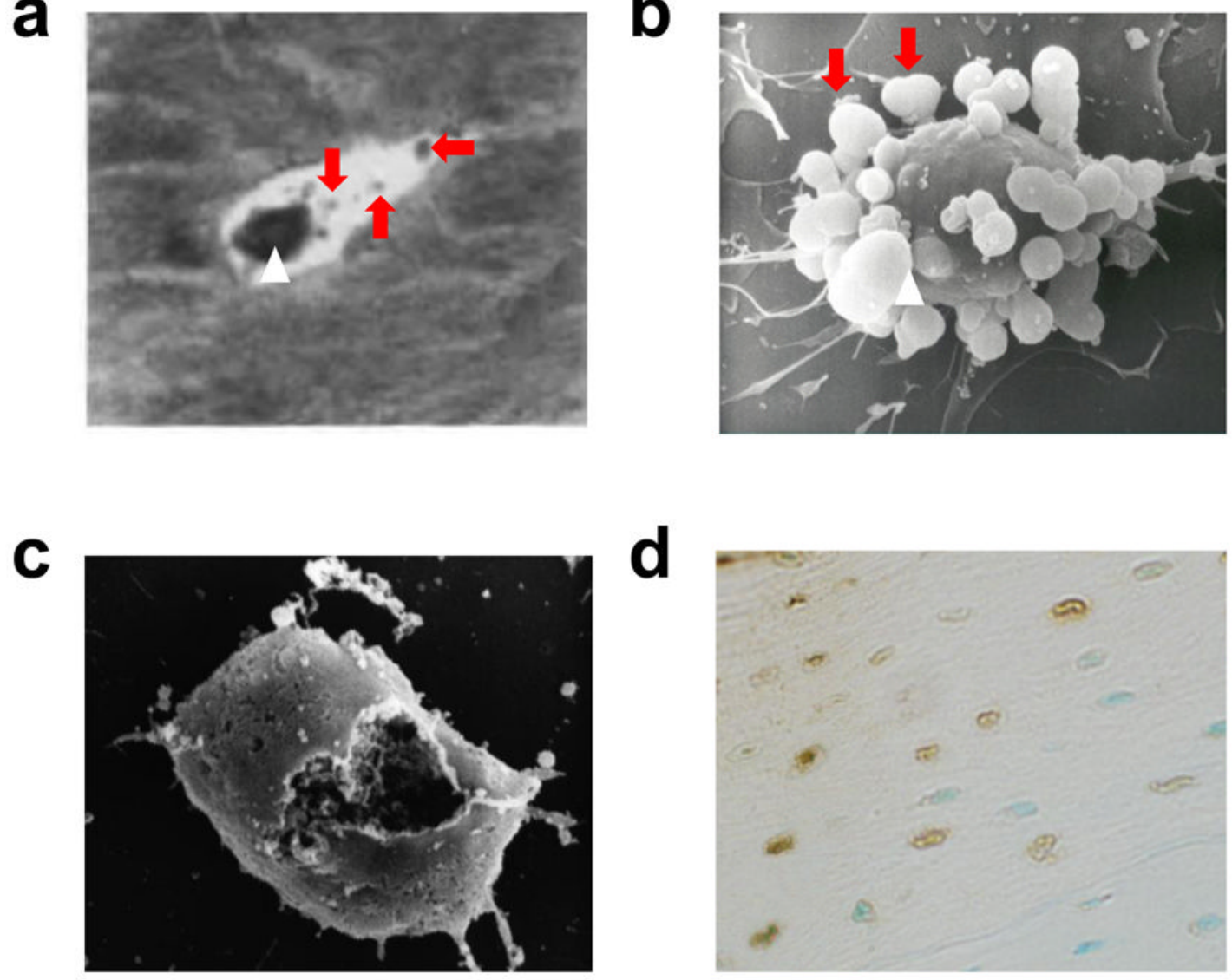

Figure 1.

Morphology of apoptotic osteocytes. a. Brightfield image of osteocyte lacuna in human infant calvarial bone containing a cell with condensed chromatin (arrowhead) and spherical structures resembling apoptotic bodies (arrows). b. Scanning electron microscope (SEM) image of apoptotic osteocyte-like MLO-Y4 cells demonstrating extensive blebbing (arrowhead) which will become apoptotic bodies (arrows). c. SEM image of necrotic swollen MLO-Y4 cell with ruptured cell membrane, which contrasts with the cell shrinkage seen in apoptotic cells. d. Active caspase-3 immunostaining (brown) in osteocytes near sites of microdamage in mouse bone. Viable osteocytes are blue. Image provided courtesy of O. Kennedy, Ph.D. and M.B. Schaffler, Ph.D. of the City College of New York. 


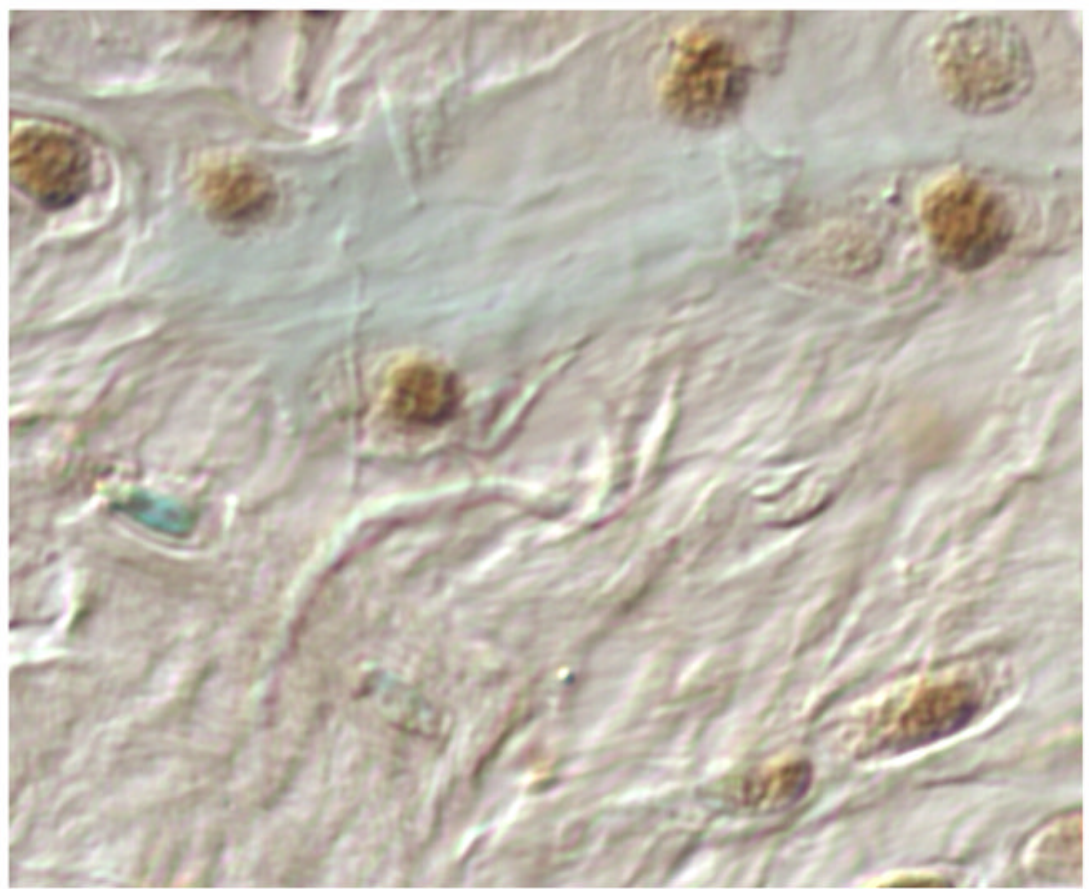

Figure 2.

ISEL-labeled (brown) apoptotic osteocytes with condensed nuclei are plentiful in murine vertebral cortical bone after 28 days of prednisone administration. 


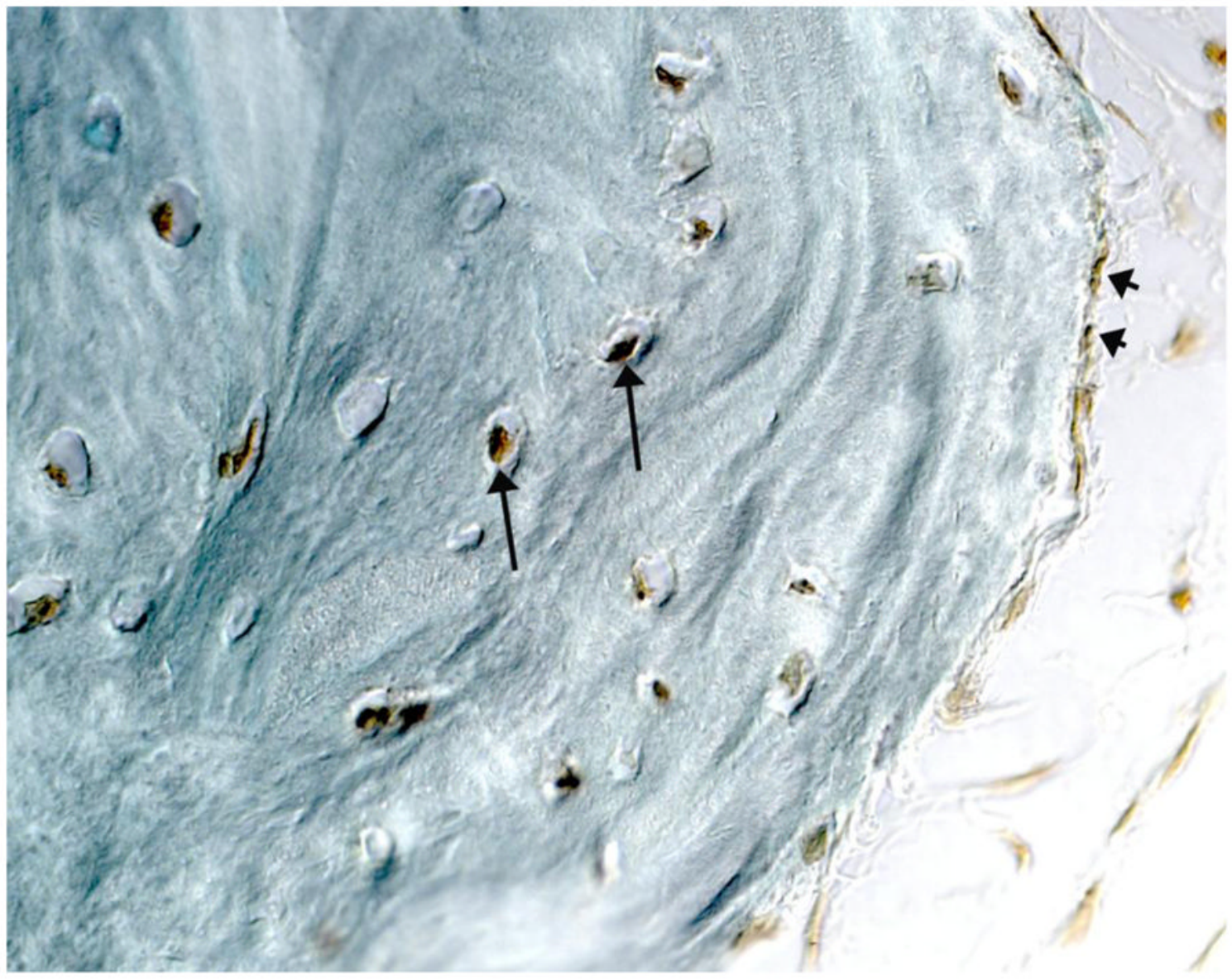

Figure 3.

Abundant apoptotic osteocytes (TUNEL) (long arrows) and lining cells (short arrows) are present in sections of human whole femoral heads obtained during total hip replacement for glucocorticoid-induced osteonecrosis. Empty osteocytic lacunae are rare. 


\section{Table 1}

Histologic detection of apoptotic osteocytes in vivo

\begin{tabular}{|c|c|c|}
\hline measurement & strengths & weaknesses \\
\hline Empty lacunae & $\begin{array}{l}\text { Simple observation of fixed bone } \\
\text { samples }\end{array}$ & $\begin{array}{l}\text { False negatives caused by cell shrinkage or fragmented nucleus } \\
\text { Cannot distinguish apoptosis from other forms of cell death } \\
\text { False positives due to loss of cellular material during processing }\end{array}$ \\
\hline Lactate dehydrogenase & $\begin{array}{l}\text { Identifies living vs. dead } \\
\text { osteocytes }\end{array}$ & Cannot distinguish apoptosis from other forms of cell death \\
\hline TUNEL/ISEL & $\begin{array}{l}\text { Usually distinguishes between } \\
\text { apoptosis and necrosis }\end{array}$ & $\begin{array}{l}\text { High sensitivity requires optimization and concurrent use of } \\
\text { positive and negative controls }\end{array}$ \\
\hline Active caspase- 3 immunostaining & Highly specific for apoptotic cells & May not be detectable in osteocyte remnants \\
\hline
\end{tabular}


Table 2

Regulation of osteocyte apoptosis

\begin{tabular}{|l|c|c|}
\hline & stimulatory & inhibitory \\
\hline Physiologic conditions & & \\
\hline$\bullet$ Fluid shear stress & & $\mathrm{X}$ \\
\hline$\cdot$ fatigue damage & $\mathrm{X}$ & \\
\hline$\bullet$ high bone turnover associated with growth & $\mathrm{X}$ & \\
\hline Pathophysiologic conditions & & \\
\hline$\bullet$ sex steroid deficiency & $\mathrm{X}$ & \\
\hline$\bullet$ aging & $\mathrm{X}$ & \\
\hline$\bullet$ hyperglucocorticoidism & $\mathrm{X}$ & \\
\hline$\bullet$ unloading & $\mathrm{X}$ & \\
\hline Biologic effectors & & \\
\hline$\bullet$ sex steroids & & $\mathrm{X}$ \\
\hline$\bullet$ integrin-ECM interactions & & $\mathrm{X}$ \\
\hline$\bullet$ ECM remodeling/growth factors & & $\mathrm{X}$ \\
\hline$\bullet$ MAPK and Wnt signaling & & $\mathrm{X}$ \\
\hline$\bullet$ PTH & & $\mathrm{X}$ \\
\hline$\bullet$ OPG & & $\mathrm{X}$ \\
\hline
\end{tabular}

